\title{
F20.0 Esquizofrenia
}

Esta categoria global inclui as variedades comuns de esquizofrenia, juntamente com algumas variedades menos comuns e transtornos intimamente relacionados.

\section{F20.0 - F20.3 Critérios gerais para esquizofrenia paranóide, hebefrênia, catatonica e indiferenciada}

G1. Pelo menos uma das síndromes, sintomas e sinais listados em (1) ou pelo menos dois dos sinais e sintomas listados em (2) devem estar presentes pela maior parte do tempo durante um episódio de doença psicótica que dure pelo menos um mês (ou por algum tempo durante a maioria dos dias).

(1) Pelo menos um dos seguintes deve estar presente:

(a) eco do pensamento, inserção ou roubo do pensamento ou irradiação do pensamento;

(b) delírios de controle, influência ou passividade, claramente referindose ao corpo ou aos movimentos dos membros ou a pensamentos, ações ou sensações específicos, percepção delirante;

(c) vozes alucinatórias comentando o comportamento do paciente ou discutindo entre elas sobre o paciente ou outros tipos de vozes alucinatórias vindo de alguma parte do corpo;

(d) delírios persistentes de outros tipos que sejam culturalmente inapropriados e completamente impossíveis (p.ex., ser capaz de controlar o tempo ou estar em comunicação com alienígenas de outro planeta). 
(2) Ou pelo menos dois dos seguintes:

(a) alucinações persistentes de qualquer modalidade, quando ocorrendo todos os dias por pelo menos um mês, quando acompanhadas por delírios (os quais podem ser superficiais ou parciais) sem conteúdo afetivo claro ou quando acompanhadas por idéias superestimadas persistentes;

(b) neologismos, interceptações ou interpolações no curso do pensamento, resultando em discurso incoerente ou irrelevante;

(c) comportamento catatônico, tal como excitação, postura inadequada, flexibilidade cérea, negativismos, mutismo e estupor;

(d) sintomas “negativos”, tais como apatia marcante, pobreza de discurso e embotamento ou incongruência de respostas emocionais (deve ficar claro que esses sintomas não são decorrentes de depressão ou medicação neuroléptica).

G2. Clausula de exclusão mais comumente usadas

(1) Se o paciente também satisfaz critérios para episódio maníaco ou episódio depressivo, os critérios listados em G1 (1) e G2 (2) acima devem ter sido satisfeitos antes que a perturbação do humor se desenvolvesse.

(2) O transtorno não é atribuível à doença cerebral orgânica ou a intoxicação, dependência ou abstinência relacionada a álcool ou drogas. 


\section{F20.5 Esquizofrenia residual}

A. Os critérios gerais para esquizofrenia (F20.0 - F20.3) devem ter sido satisfeitos em alguma época no passado, mas não são satisfeitos no presente momento.

B. Pelo menos quatro dos seguintes sintomas "negativos" têm estado presentes nos últimos 12 meses:

(1) lentificação psicomotora ou hipoatividade;

(2) embotamento afetivo indubitável;

(3) passividade e falta de iniciativa;

(4) pobreza da quantidade ou do conteúdo do discurso;

(5) pobre comunicação não-verbal através da expressão facial, olhar, modulação de voz ou postura;

(6) pobre desempenho social e autocuidado.

\section{F20.6 Esquizofrenia simples}

A. Há um desenvolvimento lento, porém progressivo, durante um período de pelo menos um ano, de todos os três seguintes:

(1) uma mudança significativa e consistente na qualidade global de alguns aspectos do comportamento pessoal, manifestado como perda de vontade e interesses, falta de objetivos, ociosidade, uma atitude absorta em si próprio e retraimento social;

(2) aparecimento e intensificação graduais de sintomas "negativos" tais como apatia marcante, escassez de discurso, hipoatividade, 
embotamento afetivo, passividade e falta de iniciativa e comunicação não verbal pobre (por meio de expressão facial, olhar, modulação de voz e postura);

(3) declínio marcante no desempenho social, escolar ou ocupacional.

B. Em momento algum há quaisquer dos sintomas referidos no critério G1 para F20.0 - F20.3, nem há alucinações ou delírios bem estruturados de qualquer tipo, isto é, o individuo não deve nunca ter satisfeito os critérios para qualquer outro tipo de esquizofrenia ou para qualquer transtorno psicótico.

C. Não há evidencia de demência ou de qualquer outro transtorno mental orgânico.

\section{F20.8 Outra esquizofrenia}

\section{F20.9 Esquizofrenia, não especificada}

\section{F21 Distúrbio esquizotipico}

A. O individuo deve ter manifestado, pelo menos, quatro dos seguintes por um período de pelo menos dois anos, seja continua ou repetidamente;

(1) afeto inapropriado ou constricto, com o individuo parecendo frio e distante;

(2) comportamento ou aparência que é estranho, excêntrico ou peculiar; 
(3) pobre relacionamento com os outros e uma tendência a retraimento social;

(4) crenças estranhas ou pensamento mágico influenciando o comportamento e inconsistentes com as normas subculturais;

(5) suspeita ou idéias paranóides;

(6) ruminações obsessivas sem resistência interna, freqüentemente com conteúdos dismorfofóbicos, sexuais ou agressivos;

(7) experiências perceptivas inusuais, incluindo somatossensoriais (corporais) ou outras ilusões, despersonalização ou desrealização;

(8) pensamento vago, circunstancial, metafórico, superlaborado ou freqüentemente estereotipado, manifestado por um discurso estranho ou diferente, sem incoerência grosseira;

(9) episódios quase psicóticos ocasionais e transitórios, com intensas ilusões, alucinações auditivas ou outras e idéias deliróides, usualmente ocorrendo sem provocação externa.

\section{F22 Transtorno delirantes persistentes}

\section{F22.0 Transtorno delirante}

A. Um delírio ou um conjunto de delírios relacionados, outros que não aqueles listados como tipicamentes esquizofrênicos no critério G1(1) b ou d para F20.0 - F20.3 devem estar presentes. Os exemplos mais comuns são delírios persecutórios, grandiosos, hipocondríacos, de ciúme (zelotípico) ou eróticos. 
B. $\mathrm{O}(\mathrm{s})$ delírio(s) no critério A deve(m) estar presente(s) por pelo menos três meses.

C. Os critérios gerais para esquizofrenia (F20.0 - F23.0) não são preenchidos.

D. Não deve haver alucinações persistentes em nenhuma modalidade (mas pode haver alucinações auditivas transitórias ou ocasionais que não sejam na terceira pessoa nem comentem as ações do paciente).

E. Sintomas depressivos (ou mesmo um episódio depressivo) podem estar presentes intermitentemente, desde que os delírios persistam nas ocasiões em que não há transtorno do humor.

F. Clausula de exclusão mais comumente usada. Não deve haver nenhuma evidência de transtorno mental orgânico primário ou secundário ou de um transtorno psicótico decorrente do uso de substância psicoativa.

\section{F22.8 Outro transtornos delirantes persistentes}

\section{F22.9 Transtorno delirante persistente, não especificado}

\section{F23 Transtornos psicóticos agudos e transitórios}

G1. Há um inicio agudo de delírios, alucinações, discurso incompreensível ou incoerente ou qualquer combinação desses. $\mathrm{O}$ intervalo de tempo entre o primeiro aparecimento de quaisquer sintomas psicóticos e a apresentação do transtorno completamente desenvolvido não deve exceder duas semanas. 
G2. Se estados transitórios de perplexidade, falso reconhecimento ou comprometimento da atenção e da concentração estão presentes, eles não preenchem os critérios para obnubilação de consciência organicamente causada.

G3. O transtorno não satisfaz os critérios sintomáticos para episódio maníaco, episódio depressivo ou transtorno depressivo recorrente.

G4. Há evidência insuficiente de uso recente de substância psicoativa para preencher critérios para intoxicação, uso nocivo, dependência ou estado de abstinência. O uso moderado continuado e largamente inalterado de álcool ou drogas em quantidades ou com a freqüência nas quais o individuo esta acostumado não necessariamente exclui o uso de, isto deve ser decidido por julgamento clinico e pelas exigências do projeto de pesquisa em questão.

G5. Clausula de exclusão mais comumente usada. Não deve haver transtorno mental orgânico ou perturbações metabólicas serias afetando o sistema nervoso central (não inclui parto).

\section{F24 Transtorno delirante induzido}

A. $\quad \mathrm{O}(\mathrm{s})$ individuo(s) deve(m) desenvolver um delírio ou sistema delirante originariamente mantido por outra pessoa com um transtorno classificado entre F20 - F23.

B. As pessoas envolvidas devem ter um relacionamento inusualmente próximo entre si e estar relativamente isoladas de outras pessoas. 
C. $\mathrm{O}(\mathrm{s})$ indivíduo(s) não deve(m) ter crença em questão antes do contato com a outra pessoa e não deve(m) ter sofrido de nenhum outro transtorno classificado em F20-F23 no passado.

\section{F25 Transtorno esquizoafetivos}

Nota. Este diagnóstico depende de um "balanço" aproximado entre o número, a gravidade e a duração dos sintomas esquizofrênicos e afetivos.

G1. O transtorno satisfaz os critérios para um dos transtornos afetivos de grau moderado ou grave, como especificado para cada categoria.

G2. Sintomas de pelo menos um dos grupos listados abaixo devem estar claramente presentes, pela maior parte do tempo, durante um período de pelo menos duas semanas.

(1) eco do pensamento, inserção ou roubo do pensamento, irradiação do pensamento;

(2) delírios de controle, influência ou passividade, claramente referindose ao corpo ou aos movimentos dos membros ou a pensamentos, ações ou sensações específicos;

(3) vozes alucinatórias comentando o comportamento do paciente ou discutindo entre elas sobre o paciente, ou outros tipos de vozes alucinatórias vindo de alguma parte do corpo;

(4) delírios persistentes, de outros tipos que sejam culturalmente inapropriados ou completamente impossíveis e não meramente grandiosos ou persecutórios; 
(5) discurso grosseiramente irrelevante ou incoerente ou uso freqüente de neologismos;

(6) aparecimento intermitente, porem freqüente, de algumas formas de comportamento catatônico, tais como postura inadequada, flexibilidade cérea e negativismo.

\section{F28 Outros transtornos psicóticos não orgânicos}

\section{F29 Psicose não orgânica, não especificada}

F30 - F39

Transtornos do humor (afetivos)

\section{F30 Episódio maníaco}

\section{F30.0 Hipomania}

A. O humor está elevado ou irritável em um grau que é definitivamente anormal para o individuo em questão e mantido por pelo menos quatro dias consecutivos.

B. Pelo menos três dos seguintes sinais devem estar presentes, levando a alguma interferência com o funcionamento pessoal na vida diária:

(1) atividade aumentada ou inquietação física;

(2) loquacidade aumentada; 
(3) distraibilidade ou dificuldade de concentração;

(4) aumento da energia sexual;

(5) diminuição da necessidade de sono;

(6) leve excesso de gastos ou outros tipos de comportamento imprudente ou irresponsável;

(7) sociabilidade aumentada ou excesso de familiaridade.

C. O episódio não satisfaz os critérios para mania, transtorno afetivo bipolar, episódio depressivo, ciclotimia ou anorexia nervosa.

D. Cláusula de exclusão mais comumente usada. O episódio não e atribuível a uso de substância psicoativa ou a qualquer transtorno mental orgânico.

\section{F30.1 Mania sem sintomas psicóticos}

A. O humor está elevado ou irritável em um grau que é definitivamente anormal para o individuo em questão. A alteração de humor deve ser proeminente e mantida por pelo menos uma semana (a menos que seja grave o suficiente para exigir internação hospitalar).

B. Pelo menos três dos seguintes sinais devem estar presentes (quatro se o humor estiver meramente irritável), levando a uma interferência grave com funcionamento pessoal na vida diária:

(1) atividade aumentada ou inquietação física;

(2) loquacidade aumentada (“pressão de fala”);

(3) fuga de idéias ou a experiência subjetiva de pensamento acelerado;

(4) perda das inibições sociais normais, resultando em comportamento inapropriado para as circunstâncias; 
(5) diminuição da necessidade de sono;

(6) auto-estima inflada ou grandiosidada;

(7) distraibilidade ou mudanças constantes em atividades ou planos;

(8) comportamento temerário ou imprudente, cujos riscos o individuo não reconhece;

(9) energia sexual marcante ou indiscrições sexuais.

C. Não há alucinações ou delírios, embora transtornos perceptivos possam ocorrer (p. ex., hiperacusia subjetiva, apreciação de cores como especialmente vividas).

D. Cláusula de exclusão mais comumente usada. O episódio não é atribuível a uso de substância psicoativa ou a qualquer transtorno mental orgânico.

\section{F30.2 Mania com sintomas psicóticos}

A. O episódio satisfaz os critérios para mania sem sintomas psicóticos, com exceção do critério C.

B. O episódio não satisfaz simultaneamente os critérios para esquizofrenia ou transtorno esquizoafetivo.

C. Estão presentes delírios ou alucinações, outros que não aqueles listados como tipicamente esquizofrênicos no critério G1(1)b, c e d para F20.0 F20.3. Os exemplos mais comuns são aqueles com conteúdo grandioso, auto-referente, erótico ou persecutório.

D. Cláusula de exclusão mais comumente usada. O episódio não é atribuível a uso de substância psicoativa ou a qualquer transtorno mental orgânico. 
F30.8 Outros episódios maníacos

F30.9 Episódio maníaco, não especificado

\section{F31 Transtorno afetivo bipolar}

Nota. Os episódios são demarcados por uma mudança para um episódio de polaridade oposta ou mista ou por uma remissão.

\section{F31.0 Transtorno afetivo bipolar, episódio atual hipomaníaco}

A. O episódio atual satisfaz os critérios para hipomania.

B. Houve pelo menos um outro episódio afetivo no passado, satisfazendo os critérios para episódio hipomaníaco ou maníaco, episódio depressivo ou episódio afetivo misto.

F31.1 Transtorno afetivo bipolar, episódio atual maníaco sem sintomas psicóticos

A. O episódio atual satisfaz os critérios para mania sem sintomas psicóticos.

B. Houve pelo menos um outro episódio afetivo no passado, satisfazendo os critérios para episódio hipomaníaco ou maníaco, episódio depressivo ou episódio afetivo misto.

\section{F31.2 Transtorno afetivo bipolar, episódio atual maníaco com sintomas psicóticos}

A. O episódio atual satisfaz os critérios para mania com sintomas psicóticos. 
B. Houve pelo menos um outro episódio afetivo no passado, satisfazendo os critérios para episódio hipomaníaco ou maníaco, episódio depressivo ou episódio afetivo misto.

\section{F31.3 Transtorno afetivo bipolar, episódio atual depressivo leve ou moderado}

A. O episódio atual satisfaz os critérios para um episódio depressivo de gravidade leve ou moderado.

B. Houve pelo menos um outro episódio afetivo no passado, satisfazendo os critérios para episódio hipomaníaco ou maníaco ou episódio afetivo misto.

F31.4 Transtorno afetivo bipolar, episódio atual depressivo grave sem sintomas psicóticos

A. O episódio atual satisfaz os critérios para um episódio depressivo grave sem sintomas psicóticos

B. Houve um pelo menos um episódio hipomaníaco ou maníaco ou episódio afetivo misto, bem caracterizado no passado.

F31.5 Transtorno afetivo bipolar, episódio atual depressivo grave com sintomas psicóticos

A. O episódio atual satisfaz os critérios para um episódio depressivo grave com sintomas psicóticos

B. Houve um pelo menos um episódio hipomaníaco ou maníaco ou episódio afetivo misto, bem caracterizado no passado. 


\section{F31.6 Transtorno afetivo bipolar, episódio atual misto}

A. O episódio atual e caracterizado por uma mistura ou então uma rápida alternância (dentro de poucas horas) de sintomas hipomaníacos, maníacos e depressivos.

B. Tanto sintomas maníacos como os depressivos devem ser proeminentes a maior parte do tempo, durante um período de pelo menos duas semanas.

C. Houve pelo menos um episódio hipomaníaco ou maníaco, episódio depressivo ou episódio afetivo misto, bem caracterizado, no passado.

\section{F31.7 Transtorno afetivo bipolar, atualmente em remissão}

A. O estado atual não satisfaz os critérios para o episódio depressivo ou maníaco de qualquer gravidade, nem para qualquer outro transtorno de humor (possivelmente para reduzir o risco de futuros episódios).

B. Houve pelo menos um episódio hipomaníaco ou maníaco bem caracterizado no passado e sem adição, pelo menos, um outro episódio efetivo (hipomaníaco ou maníaco, depressivo ou misto).

\section{F31.8 Outros transtornos afetivos bipolares}

\section{F31.0 Transtorno afetivo bipolar não especificado}

\section{F32 Episódio depressivo}




\section{F32.3 Episódio depressivo com sintomas psicóticos}

A. Os critérios gerais para episódio depressivo (F32) devem ser satisfeitos.

B. Os critérios para episódio depressivo grave sem sintomas psicóticos devem ser satisfeitos com exceção do critério D (não deve haver alucinação, delírio ou estupor depressivo).

C. Os critérios para esquizofrenia (F20.0 - F20.3) ou transtorno esquizoafetivo não são satisfeitos.

D. Qualquer um dos seguintes deve estar presente:

(1) delírios ou alucinações, outros que não aqueles listados como tipicamente esquizofrênicos no critério G1(1)b, c, d para F20.0 - F20,3 (isto é, delírios outros que não aqueles que são completamente impossíveis ou culturalmente inapropriados e alucinações que não seja na terceira pessoas ou fazendo comentários);

(2) estupor depressivo; 


\section{F32 Episódio depressivo}

G1. O episódio depressivo deve durar pelo menos duas semanas.

G2. Não houve sintomas hipomaníaco ou maníacos o suficiente para satisfazer os critérios para episódio hipomaníaco ou maníacos em qualquer época da vida do individuo;

G3. Clausula de exclusão mais comumente usada. O episódio não é atribuível ao uso de substância psicoativa ou a qualquer transtorno mental orgânico. 